\title{
Experienced Barriers in Web Applications and Their Comparison to the WCAG Guidelines
}

\author{
Diana Ruth-Janneck \\ Technical University of Dresden, Private Lectureship Applied Computer Science \\ 01062 Dresden, Germany \\ diana.ruth-janneck@pdai.de
}

\begin{abstract}
A German organization established the study "Web 2.0 Accessible" in 2008 which asked Internet users with disabilities about the barriers they experience when using websites and web applications. This paper gives some interesting facts of the study which are useful for the design and implementation of accessible web applications. Therefore it raises classifications of barriers in various dimensions we have registered in the German study regarding the use of web applications by persons with disabilities and correlate these barriers with the WCAG 2.0 Guidelines and Principles to support the facts of the study. Furthermore the results will be supported by key results of other studies regarding web accessibility. The objective of this paper is to identify in practise experienced barriers for people with disabilities using websites and applications.
\end{abstract}

Keywords: Web Accessibility, Barriers, People with disabilities using the Internet, WCAG 2.0, Study Web2.0 Accessible.

\section{Introduction}

In our today's more and more digital world, it is necessary that web pages and web applications are accessible for all users and especially for users with disabilities. More than 8.6 million people with disabilities live in Germany. Their number represents about $10.5 \%$ of the German population [1]. The European Commission assumes that one fifth of the working age population have a disability and almost $60 \%$ of the population would be likely to benefit from web accessibility [2]. And this number does not include elderly people, which often experience similar problems to access web pages and their interactions. Thus, accessible web applications can be an important step to an inclusive web for all. But nowadays there are many problems and restrictions for users with disabilities. A German study was established in 2008 for register the actual state of the art regarding the Internet access by people with disabilities. The results provide important and practically relevant aspects for designers, developers and evaluators of accessible web applications. It outlines the most critical technical, design and editorial barriers for different user groups with disabilities. These results are very useful in connection with the WCAG 2.0 Checkpoints and the statements of the questioned user. 
This paper gives an insight into the German study "Web2.0 Accessible” [3] at first. The most important applications for Internet users with disabilities and the applications showing the highest problem rates compiled in the study are especially interesting here. The second part of the paper consists of the comparison of the extracted most critical issues of web applications with the actual WCAG 2.0 Checkpoints [4]. At the end of this paper, the most important aspects of accessible web applications are summarized.

\subsection{Methodology and Related Works}

The following statements result from a qualitative analysis of the data from the online survey in connection with the transcription of the statements given in the interviews. The most important applications for Internet users with disabilities have been identified due to the highest usage frequencies in the different user groups. These applications have been compared to the recorded problem rates and to the interviewees' statements. These results have been the basis of developing the most important accessibility issues and critical aspects for the different user groups with disabilities and of connecting them with the corresponding WCAG Checkpoints.

The facts about the barriers which are experienced in practice by people with disabilities are supported by the results of two other studies concerning web accessibility with user involvement. One important study was established by the Disability Rights Commission (DRC) in the UK [5] in 2004. It is a large-scale study which tested 1.000 popular British sites for technical compliance with the WCAG 1.0 Checkpoints. Furthermore, $10 \%$ of these sites were tested with a group of 50 users with different impairments and by accessibility experts. The user statements and experienced key problems are the most interesting points for this work. Another helpful survey was a study on screen readers with 100 blind users in the US in 2007 by Lazar et.al. [6]. This study, whose findings have supported our results, recorded frustrations for blind users using the web. A lot of other studies and research look for e.g. the compliance of government websites (e.g. MeAC [2] or Lopes et.al.[7]) or of popular websites (e.g. Sullivan et.al. [8]) with the WCAG or with accessibility barriers for older people (e.g. Sayago et.al. [9]).

\section{The German Study "Web 2.0 Accessible"}

The German organization “Aktion Mensch” established the study "Opportunities and Risks of the Internet of the Future from the Perspective of People with Disabilities" [3] regarding the use of web2.0 applications by disabled people in 2008 in whose evaluation the author significantly participated. This study offers reliable statistical data concerning the use of web applications by people with disabilities as well as which barriers and problems of use occur. It forms the statistical and qualitative basis for the statements and classifications made in this paper. 


\subsection{Methodology of the Study}

The study involved three steps of the inclusion of data in order to collect both quantitative and qualitative data. On the one hand, experts from science and self-help organizations have been consulted to capture the current state of knowledge on Internet use by people with disabilities. Additionally, experienced Internet users with disabilities were questioned in group interviews about their experiences and habits with web2.0 applications as well as about the barriers they experienced. The data from these steps about possible barriers in web applications were used for the concrete realization of the online survey which measured the scope of these barriers.

Disabled Internet users were questioned about use habits and barriers with the help of an accessible online survey including audio files and sign language videos. The online survey was organized in multiple areas to acquire several data [3, 10]:

- Demographic characteristics including kinds of disabilities and frequency of use of the web (participants without an impairment or with sporadic use were excluded here)

- Data on the use of assistive technologies and technical equipment

- Free text answers to "What is the best thing on the Internet for you?" and "What is the most annoying thing on the Internet for you?"

- Data on the use behavior and intentions of use by selection from given lists ("I use websites for..." and "With the Internet I can ...")

- Prominence of different popular websites ("Which kinds of website do you know?" If the participant does not know the website he will not get more questions about.)

- Questions about the prominence, the share of use (from a list) and experienced barriers for the familiar websites; for every barrier noticed: free text answer for more explanation and a question about the kind of barrier (not operable, not perceivable, not understandable, no orientation)

- Graduated compliance for special advantages by using websites for disabled Internet users in a list of statements.

The survey was supported with the help of special German websites for people with disabilities and self-help organizations in January and February 2008. A total of 671 people with disabilities have completed the questionnaire. This allows us to make precise statements on the test results from the perspective of the different kinds of disabilities, but not on all Internet users in general or all users with disabilities because of the non-representative basis [3].

\subsection{Facts about the Study}

People with different kinds of disabilities were interviewed during the study. In total, 10 people were interviewed as experts, 57 people were questioned in groupinterviews and 671 people have completed the online-survey. The following table gives the total number of questioned people with the different types of disabilities and the assistive technologies used most often in these groups [3]. 
table 1. Numbers of Questioned People and the Assistive Technologies Used Most Often

\begin{tabular}{|l|l|l|}
\hline Type of Disability & $\begin{array}{l}\text { Number of } \\
\text { Questioned } \\
\text { People }\end{array}$ & Assistive Technologies Used Most Often \\
\hline Visual Impairment & 133 & $\begin{array}{l}\text { Screen magnifier (56\%), audio response } \\
(22 \%), \text { Screen reader (21\%) }\end{array}$ \\
\hline Blindness & 124 & $\begin{array}{l}\text { Screen reader (91\%), Braille terminal } \\
(85 \%), \text { audio response (70\%) }\end{array}$ \\
\hline Hardness of Hearing & 96 & $\begin{array}{l}\text { Audio response (16\%), screen magnifier } \\
(13 \%)\end{array}$ \\
\hline Deafness & 260 & $\begin{array}{l}\text { Screen magnifier (7\%), audio response } \\
(6 \%)\end{array}$ \\
\hline $\begin{array}{l}\text { Motor and Dexterity } \\
\text { Impairments }\end{array}$ & 75 & $\begin{array}{l}\text { Special scroll wheels or trackball mouse } \\
(20 \%), \text { special keyboard/on-screen key- } \\
\text { board (17\%), voice recognition software } \\
(16 \%)\end{array}$ \\
\hline $\begin{array}{l}\text { Learning and Cognitive } \\
\text { Impairments }\end{array}$ & 35 and 13 & $\begin{array}{l}\text { Screen magnifier (32\%), audio response } \\
(24 \%), \text { spell assist programs and voice- } \\
\text { recognition facilities (20\%) }\end{array}$ \\
\hline $\begin{array}{l}\text { Screen magnifier (22\%), audio response } \\
(20 \%), \text { Screen reader (13\%) }\end{array}$ \\
\hline
\end{tabular}

The number of respondents in the groups Dyslexia and Learning and Cognitive Impairments was too small to make reliable statements about the barriers and strategies, but only tendencies could be deduced from the answers. We can make some statistical and qualitative statements about the experienced barriers and useful strategies concerning the other groups. The information is complemented by free text answers given in the online survey and statements from the interviews. This has given us some interesting and concrete facts about the strategies of and barriers for Internet users with disabilities.

These different kinds of disabilities are summarized for the following considerations into groups because the Internet is used with the help of similar assistive technologies (AT) or use strategies due to the respective disability-related restrictions. A definition and differentiation of the types of disabilities cannot be given at this point. All in all, it is remarkable that the magnification software was considered as of significant usage share by all surveyed user groups which is probably due to multiple restrictions or simplification of the perception of contents.

${ }^{1}$ Because of 82 participants with multiple impairments, the total number of questioned people is less then the sum over all user groups. These persons provide data for each affected user group with disabilities. 
The people questioned distinguished themselves by a high technical standard of the Internet access so that it can be assumed that identified barriers are not caused by lacking technical equipment. The results of the study proved furthermore that the interviewees are very experienced in dealing with Internet applications, they show high usage frequency and have above-average experiences with web2.0 applications so that also factors like insecurity or low affinity to the Internet can be excluded [3]. A comparison with an annual German study (ARD/ZDF-Online-Study 2010) about the use of the Internet, which takes the whole German population into account, shows that Internet users with disabilities use the web about 6.5 days/week, internet users without disabilities use it only 5.1 days/week [1]. This fact underlines another result of the study "Web 2.0 Accessible": the Internet is one of the most important things in daily life for users with disabilities and it can help to live in a far more independent way. It is a tool for information and communication. For more than $40 \%$ of the questioned users with disabilities, Internet is a tool for the compensation of disabilityrelated disadvantages [3].

Web accessibility is a very important fact for all questioned Internet users, particularly for blind users. $88 \%$ of them chose "accessibility is very important for me”. Furthermore, $82 \%$ of the questioned people with blindness said that barriers disturb their access to the content. But web accessibility is also very important for $70 \%$ of the users with deafness and $70 \%$ of the users with cognitive impairments. The users with visual impairments have the smallest coincidence with 59\% [3]. This is explainable with the circumstance that these users can manage accessibility problems in different ways. Accessibility problems are often invincible for users who are dependent on assistive technologies.

\subsection{The Most Important Applications}

The study inquired, among other things, prominence, use and problems in dealing with various web2.0 applications and their functions. The most significant shares of utilization (more than $60 \%$ of use) and the highest problem rates (more than $20 \%$ ) should indicate the value of certain application classes for the different user groups in the following comparison. Thus, it can be derived which applications are used very often and in which of them problems are frequently noticed.

Applications with high usage and problem rates should increase the efforts with respect to accessibility. The shares of use given in the table were determined during the quantitative part of the study by the online survey. It indicates the proportion of those who have used or tried to use the application. The problem rate is calculated from the quotient of the problems and the use / attempt to use and provides a projection of the anticipated problems in the use of the application by the user groups [3]. 
table 2. Maximum Share of Use and Rate of Problems ${ }^{2}$ [modified according to [3, 11])

\begin{tabular}{|c|c|c|c|c|c|}
\hline & $\begin{array}{l}\text { Visually Handi- } \\
\text { capped }\end{array}$ & Blind & $\begin{array}{l}\text { Hard of } \\
\text { Hearing }\end{array}$ & Deaf & $\begin{array}{l}\text { Motor Dis- } \\
\text { abilities }\end{array}$ \\
\hline $\begin{array}{l}\text { Share of } \\
\text { Use }> \\
60 \%\end{array}$ & $\begin{array}{l}\text { Read wikis } \\
(79 \%), \\
\text { Make user regis- } \\
\text { tration }(75 \%) \text {, } \\
\text { View photos } \\
(70 \%) \text {, } \\
\text { View videos } \\
(61 \%)\end{array}$ & $\begin{array}{l}\text { Read wikis } \\
(85 \%) \text {, } \\
\text { Make user } \\
\text { registration } \\
(80 \%) \text {, } \\
\text { Write com- } \\
\text { ments } \\
(60 \%) \text {, } \\
\text { Listen to } \\
\text { podcasts } \\
\text { (60\%) }\end{array}$ & $\begin{array}{l}\text { Read } \\
\text { wikis } \\
(68 \%), \\
\text { View } \\
\text { photos } \\
(60 \%)\end{array}$ & $\begin{array}{l}\text { Read wikis } \\
(61 \%), \\
\text { View photos } \\
(60 \%)\end{array}$ & $\begin{array}{l}\text { Read wikis } \\
(84 \%) \text {, } \\
\text { Make user } \\
\text { registration } \\
(71 \%) \text {, } \\
\text { View pho- } \\
\text { tos (65\%) }\end{array}$ \\
\hline $\begin{array}{l}\text { Rate of } \\
\text { Pro- } \\
\text { blems > } \\
20 \%\end{array}$ & $\begin{array}{l}\text { Make user regis- } \\
\text { tration (41\%), } \\
\text { Edit user profile } \\
\text { (30\%), } \\
\text { View videos } \\
\text { (28\%), } \\
\text { Write comments } \\
\text { (25\%), } \\
\text { Read weblogs } \\
\text { (25\%), } \\
\text { View photos } \\
\text { (23\%), } \\
\text { Listen to pod- } \\
\text { casts (21\%) }\end{array}$ & $\begin{array}{l}\text { Make user } \\
\text { registration } \\
(69 \%), \\
\text { Edit user } \\
\text { profile } \\
\text { (58\%), } \\
\text { View videos } \\
\text { (31\%), } \\
\text { Write com- } \\
\text { ments } \\
\text { (30\%) }\end{array}$ & $\begin{array}{l}\text { View } \\
\text { videos } \\
(33 \%)\end{array}$ & $\begin{array}{l}\text { Read wikis } \\
(26 \%) \text {, } \\
\text { View videos } \\
(23 \%) \text {, } \\
\text { Write com- } \\
\text { ments (21\%) }\end{array}$ & $\begin{array}{l}\text { Write } \\
\text { comments } \\
(28 \%), \\
\text { Edit user } \\
\text { profile } \\
(20 \%)\end{array}$ \\
\hline $\begin{array}{l}\text { Prob- } \\
\text { lematic } \\
\text { Aspects }\end{array}$ & $\begin{array}{l}\text { Captchas, } \\
\text { Completion of } \\
\text { forms, } \\
\text { Visual fields of } \\
\text { applications }\end{array}$ & $\begin{array}{l}\text { Captchas, } \\
\text { Completion } \\
\text { of forms, } \\
\text { Visual } \\
\text { fields of } \\
\text { applications }\end{array}$ & $\begin{array}{l}\text { Quality } \\
\text { of me- } \\
\text { dia files, } \\
\text { Audi- } \\
\text { tory } \\
\text { fields }\end{array}$ & $\begin{array}{l}\text { Quality of } \\
\text { media files, } \\
\text { Linguistic } \\
\text { problems, } \\
\text { Auditory } \\
\text { fields }\end{array}$ & $\begin{array}{l}\text { Navigation, } \\
\text { orientation } \\
\text { and oper- } \\
\text { ability of } \\
\text { web appli- } \\
\text { cations }\end{array}$ \\
\hline
\end{tabular}

\footnotetext{
2 There are no reliable data about the groups Dyslexia, Learning disabilities and Cognitive Impairments given because the basis of results is too small (see table 1).
} 
Across all user groups, which have been questioned, the highest shares of use are to be registered concerning the reading of wikis. This kind of website causes less problems (problem rate between 6\% and 13\%) for the most user groups. Deaf Internet users show the highest problem rate here (26\%) because of problems in understanding the content ${ }^{3}$. The questioned participants mainly have problems with comprehensibility of the (user-generated) content (48\% of all who have problems) and orientation on the website (39\% of all who have problems) because of numerous links.

High shares of use are also mentioned for user registration in all groups. This is because a lot of web applications and services require a registration for full access. Problems here are based on inaccessible forms from the technical point of view and incomprehensibility of the explanations for the required data from the editorial point of view. Thus, $73 \%$ of those who have problems with a user registration chose "not perceivable" and 66\% chose for "not operable" [3]. Visually impaired, blind and physically disabled persons are mostly confronted with these problems.

Much the same applies for editing user profiles and the use of forms. Forms and in particular Captchas limit the independent use here. Especially users who use AT have problems with orientation on the website (53\% of all who have problems), with operability of the form elements (50\% of all who have problems) and with the perceptibility of the elements (47\% of all who have problems). Similar problems are noticed on form-based and editor-based applications such as the writing in wikis or weblogs. The users show great interest in writing comments (e.g. 60\% of blind users), but problems like those mentioned above limit the easy access and interaction [10].

Moreover, the table shows that partially sighted and blind users indicated problems with the use of primarily visual media like photos and videos. Disability-related restrictions and bad media quality are the main cause of it. Even hearing impaired and deaf Internet users stated problems with visual media which are caused by insufficient media quality as well as with the unlimited operability and availability of appropriate media players. Statements from free text answers [3] have given some more aspects: too small images, too small video windows or poor resolution, audio streams which are too noisy or added with background noise, unavailability of subtitles or sign language videos. Despite problems in access and use of media content, show the high share of use of visual and auditory content in all questioned user groups big interests for these. This fact should emphasize the importance of making this content as accessible as possible for all.

\section{Comparison of the Results with WCAG}

Various areas of accountability and contributors in the development and operation process of a web application have to be determined for the prevention of barriers.

${ }^{3}$ The linguistic barrier concerning reading and writing, for instance of wikis and comments, applies to deaf users because the German sign language differs substantially from the spoken and written language. Thus, deaf people experience a more difficult access to the written language. 
They should be responsible for ensuring accessibility in their respective field of action. For the following comparison of the study results with the WCAG 2.0 Checkpoints (CP), the facts have been organized in relation to the area of accountability. Different areas of accountability have been defined for this purpose which correlates to the different positions in the development process of web applications like developers, authors, designers and customers. According to the description of the "Essential Components of Web Accessibility" from the W3C Web Accessibility Initiative ${ }^{4}$ (WAI) Group [12] which presents interdependencies between the components and roles, the four different areas of accountability are not independent at all. It is for this reason that some items in the tables are assigned to several areas. The four defined areas are: technical aspects, editorial aspects, design aspects and organizational aspects of web accessibility. A description of each can be found in the following paragraphs.

Furthermore, three tables concerning technical barriers, editorial barriers and design barriers have been developed. In the planning and development of a web application, the different person in charge can consult the specific table to look up the most critical aspects and use cases compiled during the study und which WCAG Checkpoint correlates to them. In connection with the guidelines and technical documents of the W3C WAI Group, the responsible person can choose the relevant checkpoints and select the corresponding success criterion and best practise.

For the comparison, the items of the classifications of barriers published in [11 and 13] were each collated with the WCAG 2.0 Checkpoints. For the better readability the results have been spread into one table for each area of accountability. Quantitative results cannot be given for the aspects in the tables because for one thing the items are grouped according to the impairment groups and for another thing the items are not exactly a part of the survey. The items in the tables are based on the qualitative analysis of the survey and the interviews which figured out the most critical aspects in web applications today.

\subsection{Technical Aspects}

The area of technical aspects includes all critical aspects based on technical restrictions, conditions or implementations: e.g. used techniques (e.g AJAX, JavaScript), programming styles and restrictions in hard- and software because of assistive technologies (AT). Examples for these are Captchas, insufficient operability of flashplayers or missing semantics and markups in web forms. Web programmers, service providers and producers of utilities and AT are responsible for these aspects [13]. Guidelines for these groups are e.g. the documents from the W3C WAI: WCAG, UAAG and ATAG and evaluation tools like validators.

The following table shows the most important technical based accessibility issues of the different user groups in connection with the corresponding WCAG Checkpoints. All in all it is remarkable that technical barriers have a big influence on the operability of the applications with the used AT. So it is conspicuous that the user groups which

\footnotetext{
${ }^{4}$ http://www.w3.org/WAI/guid-tech.html
} 
are reliant on AT recognized most barriers. In some cases, these barriers hinder the independent use of the application by the affected user groups.

table 3. The Most Important Technical Based Accessibility Issues for the Different User Groups in Connection with the Corresponding WCAG Checkpoints

\begin{tabular}{|l|l|l|}
\hline \multirow{4}{*}{ Type of Disability } & Technical Aspects & $\begin{array}{l}\text { WCAG Check- } \\
\text { points }\end{array}$ \\
\hline \multirow{5}{*}{ General } & Operability, & 2 \\
\cline { 2 - 3 } & Semantics of web forms \& buttons, & $1.3,4.1$ \\
\cline { 2 - 3 } & Error messages, & $3.1,3.3$ \\
\cline { 2 - 3 } & Semantics of media content, & $1.3,4.1$ \\
\cline { 2 - 3 } & Operable \& available player & 1.1 \\
\hline \multirow{5}{*}{ Visual Impairments } & Forms in PDF, & 3.3 \\
\cline { 2 - 3 } & Captchas, & 1.1 \\
\cline { 2 - 3 } & Operable forms \& editors, & 2.1 \\
\cline { 2 - 3 } & $\begin{array}{l}\text { Operability with AT (e.g. JavaScript, } \\
\text { flash, AJAX) \& without mouse }\end{array}$ & $2.1,2.4,4.1$ \\
\hline Hearing Impairments & Download \& control of podcasts & 2.2 \\
\hline \multirow{5}{*}{$\begin{array}{l}\text { Motor and Dexterity } \\
\text { Impairments }\end{array}$} & Operability of: web forms, & $2.1,3.3,4.1$ \\
\cline { 2 - 3 } & buttons, & $2.1,2.4,4.1$ \\
\cline { 2 - 3 } & drop-down-menus, & $2.4,4.1$ \\
\cline { 2 - 3 } & players, & $2.1,2.2,2.4,4.1$ \\
\cline { 2 - 3 } & activation of links, & $2.1,4.1$ \\
\cline { 2 - 3 } & Operability without mouse & \\
\hline
\end{tabular}

It is not surprising that visual impaired, blind and physically impaired Internet users have most problems resulting from technical problems with their AT. Most of the problems occur during the interaction with interactive elements and forms without a mouse.

\subsubsection{Registration, Forms and Buttons}

Forms and corresponding buttons e.g. for user registration or buying processes are a relevant part of a web page and have to work for all interested users. But there are big problems with forms and buttons in a technical and in a cognitive way. This is underline with the rate of problems in table 2 where e.g. $69 \%$ of blind users probably will have problems with user registration forms. But there are also high problem rates for this type of user interaction for the other user groups. 
Problems in forms resulting from different aspects for different user groups, but the most important aspect for all user groups is the using language in forms. Users have to understand what kind of input and in which format it is expected, why this data is necessary etc. (CP 3.3). Thus, explanations and labels are the most important aspects (see also par. 3.2). But if the explanation is too long e.g. users with deafness and cognitive impairments don't understand it [3]. The DRC-study ${ }^{5}$ support these results with significant values e.g. in the group hearing impaired users for "complex terms/ language” as a key problem [5].

Furthermore, the access to forms with assistive technologies is the second big problem. This includes the labels, input elements, selection elements, submit buttons etc. Elements of forms which are not logically ordered (CP 2.4) or which are not described with all necessary mark-up (CP 3.3) can cause problems for users which are dependent on the keyboard or on the special AT-functions for forms. They can have problems to reach the actual form element, to identify the label of the form element and to reach the submit button. Especially the tab order and focus behaviour (CP 2.4 and 3.2) need attention for accessible forms. This fact was also supported by the study of Lazar et. al. [6], where "poorly designed/unlabeled forms" is the third-highest point of frustrating points in web pages.

Some participants said in the survey that there are problems with comment functions when accessing with screen readers. The AT does not recognize the written text in the forms and they can not check their comments before submitting [3]. In large forms, e.g. for comments or for text in wikis, problems can occur with the reaction of the application to user controls. Surprising action is the result. Another problem is the correct structuring and formatting of text in editor forms with AT. Participants said that they often do not format their comments or that they ask for help [3, 10].

Moreover the usability of forms in general is an important aspect which has to be well researched and realized. This includes e.g. the perceptibility of the elements and possibilities (e.g. in sliders or selection bars; CP 1.1 and 1.4), the logic and programmed sequences of the elements (especially the keyboard access and focus; CP 2.1 and 2.4) and the wording (CP 3.3) as well. Because of these several impacts all programmers and editors have to think very carefully about the realization of forms and buttons to get them accessible in a perceptible, operable, understandable and robust way.

\subsubsection{Operability with Assistive Technologies}

The operability of web pages and their functions with assistive technologies is causal for many problems for users who are dependent on AT. This key area is focus in two of four principles of the WCAG 2.0: Principle 2 Operable and Principle 4 Robust. These principles regard to keyboard navigation (CP 2.1), navigation and orientation (CP 2.4) and compatibility with current and future user agents including assistive technologies (CP 4.1). The German study find out that users often have problems with the operability of:

\footnotetext{
${ }^{5}$ There is no direct comparison possible between the statistical results of the German study and the British study because they have different scopes. But the core results of the key problems are comparable.
} 
- Forms and buttons,

- Drop-down-menus,

- Players and editors,

- Multimedia components.

The core of all these aspects is the access without a mouse (CP 2.1). This is particularly important for blind and physically impaired users. In the interviews and free text answers of the study users said that they often can't use players in multimedia sites and editors in wikis or weblogs with only a keyboard. So they have no control of multimedia content. These problems are formulated often in the interviews as well as in the free text answers fields for the applications wikis, weblogs and media sharing websites [3]. The DRC-study confirmed this with significant values for "incompatibility between accessibility software and web pages" for blind and partially sighted users [5]. In the US-Study of Lazar et al. were "conflicts between screen reader and application" the second-highest cause for frustration of blind Internet users [6].

\subsubsection{Captchas}

Captchas (CP 1.1) are a problem for 39\% of the questioned blind people and for 5\% of the questioned visual impaired people. 50 persons said that this is the main barrier for an independent user registration because a screen reader can not recognize these figures. One way for solving this problem is the possibility to listen to an audio-file which represents the Captcha but this is not a preferred way for most of blind and visual impaired people [14]. Some of them use webvisum (www.webvisum.com/) which is a firefox extension for solving graphical Captchas. The corresponding form element for the solution has to be reachable too.

\subsubsection{Conclusion for Technical Barriers}

Summarizing the technical aspects we can see that the main problems are in connection with AT. If programmers do not use all necessary mark-up, no logical structure for all elements and no alternative ways for access like audio-Captchas some users with disabilities will have big problems to interact with the application. Another important point for programmers and utility producers is the ensurance of full access and interaction with only a keyboard as input device. Furthermore, developers have to ensure the accessibility of special features like applets in Java, PDF or flash. For these objects the WCAG Checkpoints are fully applicable, e.g. keyboard access (CP 2.1), focus highlighting and order (CP 2.4), alternative text (CP 1.1), scalability (CP 1.4) etc. Central importance should be admitted also to the accessibility of web forms. These measures are beneficial to all user groups because the readability, usability and accessibility of form elements are crucial for the independent participation e.g. in social networks.

\subsection{Editorial Aspects}

Editorial and content-related barriers contain insufficient editorial or structural content preparation for Internet requirements, e.g. difficult language, missing textual 
structures or missing semantics of media content [13]. Guidelines for web editors are e.g. "European standards for making information easy to read and understand" [15]. The table shows the main problems regarding the editorial aspects of a web application. This includes the understandability of the content in general but also the understandability of all text elements of a webpage because these support the orientation, the user guidance and the content reception. One of the main interesting points in the table is the several listed issue of missing or unclear descriptions, semantics and mark-ups of media content. This means for different user groups that they have no access to the content of media because there is no alternative text (CP 1.1, 1,2, 1.3).

table 4. Critical Editorial Aspects for Different User Groups in Connection with the Corresponding WCAG-Checkpoints

\begin{tabular}{|c|c|c|}
\hline Type of Disability & Editorial Aspects & $\begin{array}{l}\text { WCAG } \\
\text { Checkpoints }\end{array}$ \\
\hline \multirow{4}{*}{ General } & Understandability, & 3 \\
\hline & Orientation \& clear arrangement, & $1.3,1.4,3.2$ \\
\hline & Quality, size \& contrasts of media content, & 1.4 \\
\hline & Descriptions of media content (alt text) & $1.1,1.2$ \\
\hline \multirow{4}{*}{ Visual Impairments } & Semantics of content, & $1.3,4.1$ \\
\hline & Descriptions of media content (alt text), & $1.1,1.2$ \\
\hline & Numerous links, & 2.4 \\
\hline & Names of links & 2.4 \\
\hline \multirow{2}{*}{$\begin{array}{l}\text { Hearing Impair- } \\
\text { ments }\end{array}$} & Videos in sign language \& with subtitles, & $1.2,1.4$ \\
\hline & Quality of podcasts & 1.4 \\
\hline $\begin{array}{l}\text { Cognitive Impair- } \\
\text { ments }\end{array}$ & Understandability & 3.1 \\
\hline $\begin{array}{l}\text { Motor and Dexterity } \\
\text { Impairments }\end{array}$ & Semantics of content & $1.3,4.1$ \\
\hline
\end{tabular}

The most important critical point over all questioned user groups is the language in the broadest sense. This means that a big part of the Internet users have small or big problems with understanding the provided information. The problems result primarily from the use of difficult language and foreign words. This is especially problematic in explanations and forms and in error messages, because users often don't understand what they have to do or what is wrong.

This is amazing and a very important fact. This means, that editors and programmers have to pay more attention to the wording and explanations. And this is an aspect which we can not check in an automatic way but only with attention to this. One solution for this is a very careful text editing and structuring of the web content. Here we have to pay more attention to the editors and their awareness of accessibility issues. 
This important fact is underline with an own principle in the WCAG: Principle 3 Understandable. It emphasizes the understandability of the information and the operation of user interfaces by users [4]. This includes in checkpoint 3.1 the content itself with identifying the language of text and mechanisms for abbreviations and pronunciations. With checkpoint 3.2 the programmers have to make the web pages predictable in operation and appearance which includes e.g. a consistent navigation and identification. That means that for example all buttons have the same wording for the same functions. In checkpoint 3.3 the avoiding of errors and mistakes is in the focus. This includes the wording of labels, error messages and suggestions.

Almost all these criterion can checked automatically whether they exist or not e.g. if there is a label element or if there is an identifier for the language of the text. But only humans can check if the wording is understandable and formulate as easy as possible. Problems with the language is not only critical for interaction but also for the user guidance in a website with the navigation and for the understandability of the provided information in general. The British DRC-study underlines these facts with their results. For all analysed user groups language can be an accessibility problem. For blind users are "incorrect or non-existent labelling of links, form elements and frames” key problems. For dyslexic users “complicated language or terminology” is a key problem. All groups have significant values for "confusing and disorienting navigation mechanisms" where the wording is a key factor for a predictable navigation [5]. This supports our findings with the problems in orientation and navigation over all questioned user groups.

The German Study, the British DRC-Study and the study from Lazar et.al. work out that another main problem are missing or unhelpful alt text for pictures and videos how it is required by CP 1.1. In all studies this is a focus issue particularly for blind users $[3,5,6]$. For hearing impaired users are the lack of alternative media for audiobased information and missing subtitles or captures key problems [3, 5]. A comparison of different accessibility studies in McEwan et.al. [16] underlines this by showing that missing alternative text for images and objects is "the most fundamental accessibility problem in commercial website development”.

In the evaluation of the interviews in connection with the survey it can extracted that the different user groups with disabilities have different problems with the language. Visual impaired and blind users have often problems if the wording in the navigation is not clear and easy and when headlines not describe what the content represent [3, 6]. Users with hearing impairments, deafness and with cognitive impairments have mostly problems with the understanding of the content especially in long text $[3,5]$. Additional they have problems in writing text like in comments or wikis because they are often not very confident with the written word and that's why they are scared about the reaction of other users. This is one reason why these user groups use functions like comments with below average in relation to the other questioned user groups [3].

For summarizing this point the following list of aspects is helpful to pay attention for the critical issues concerning the language and understandability of text in websites [11]:

- Difficult language and foreign words, 
- Content in general,

- Alt-Text and descriptions of media content,

- Explanations and agreements,

- Error messages and suggestions,

- Expected inputs,

- Names of links and in navigation.

\subsection{Design Aspects}

In addition to technical and editorial barriers also design barriers can have a deep impact to the accessibility of websites and applications. These aspects influence the user guidance and perceptibility of functions and not at least the aesthetic impression to the user. Design barriers based on inadequate accessible design of user interfaces, e.g. insufficient contrast, background images or too small font sizes [13]. The following table relate the most critical design based issues due to the accessibility of the web content and functionality in connection with the corresponding WCAG Checkpoints.

table 5. Critical Design Related Aspects for Different User Groups and the Corresponding WCAG Checkpoints

\begin{tabular}{|l|l|l|}
\hline Type of Disability & Design Aspects & $\begin{array}{l}\text { WCAG } \\
\text { Checkpoints }\end{array}$ \\
\hline \multirow{4}{*}{ General } & Perceptibility, & 1 \\
\cline { 2 - 3 } & Orientation \& clear arrangement, & $1.3,1.4,3.2$ \\
\cline { 2 - 3 } & Perceptibility of functions, & $1.4,2.4$ \\
\cline { 2 - 3 } & Quality, size \& contrasts of media content & 1.4 \\
\hline \multirow{3}{*}{ Visual Impairments } & Quality of pictures, & 2.3 \\
\cline { 2 - 3 } & Optimization for certain screen resolution, & 1.4 \\
\cline { 2 - 3 } & Size of buttons \& interactive elements & 2.4 \\
\hline $\begin{array}{l}\text { Cognitive Impair- } \\
\text { ments }\end{array}$ & Orientation \& clear arrangement & $1.3,1.4,3.2$ \\
\hline $\begin{array}{l}\text { Motor and Dexterity } \\
\text { Impairments }\end{array}$ & Arrangement of links & 2.4 \\
\hline
\end{tabular}

One of the most important and impressive fact from the study is that almost all Internet users have problems to access and interact with a web application because of less orientation and arrangement (CP 1.3, 1.4, 3.2). The main problems are poor contrast and too small font sizes (CP 1.4). The British DRC-study comes to similar results: all groups except the blind users identify "graphics and text size too small” and "inappropriate use of colors and poor contrast between content and background" as key problems [5]. Furthermore, in our study as well as in the DRC-study almost all user groups outline problems with the layout and orientation in the website: "unclear 
and confusing layout of pages" and "confusing and disorienting navigation mechanisms" are the most referred key problems.

Another important aspect is the perceptibility of functions especially in editors and players (CP 1.4, 2.4). For almost all applications with media content people formulate problems due to the non-perceptibility of functions. The impact is clear: if they can't detect or separate the functions they can't use it.

Orientation, clear arrangement (CP 1.3, 1.4, 3.2) and problems with quality, size and contrast of media content (CP 1.4) can be attributed as well to editorial as to designer aspects. On the one hand, the design should intend suitable format templates and place holders and on the other hand the editorial staff has to process contents and media for the Internet and appropriately integrate it into the format templates. Navigation and contents must be offered well and identifiably structures (paragraphs, headings) and with sufficient font size for the orientation and clear arrangement.

\subsection{Organizational Aspects}

Organizational barriers based on organizational circumstances and a lack of awareness for accessibility issues. Examples are missing budget for videos in sign language and alternative preparation. Orderers and customers are responsible for the realization of the critical factors when they have a high awareness for accessibility issues. Actually there are a lot of policies and laws for public and government websites regarding the accessibility of these for all users (compare e.g. http://www.w3.org/WAI/Policy/). The DRC-Study [5] and the MeAC-study from the European Commission [2] contain a lot of recommendations for website commissioners and organizations. The W3C resource "Developing a Web Accessibility Business Case for Your Organization" (http://www.w3.org/WAI/bcase/Overview.html) give a holistic business case for developing accessible websites and can use e.g. for orderer and customer to convince for accessibility. It describes the social, technical, financial and legal factors and impacts of accessibility.

\section{Conclusion}

Interestingly, the recorded results coincide very well with the four principles that characterize the WCAG 2.0. So the requests for perceptibility, operability and understandability have been articulated by the interviewed persons repeatedly. The principle of robustness is primarily reflected concerning the performance of web applications accessed with assistive technologies. The results presented here show the high practical relevance of both: the results of the study and the WCAG 2.0 because the problems identified in the study reflect barriers which still occur and the WCAG 2.0 documents can provide the answers for their accessible implementation.

The study has identified wiki applications, registrations and other forms and media applications as the most important applications which are very interesting for people with disabilities although they are often faced with accessibility problems. The most 
important barriers for all user groups are understandability in the broadest sense, the use of forms and the operability of multimedia components, especially with assistive technologies.

Technical problems which are for the most part caused by insufficient operability of the applications with assistive technologies are especially noticed by visually impaired, blind and physically disabled persons. Hearing impaired and deaf Internet users particularly encounter problems of understanding due to insufficient or superficial treatment of content and media in formats they understand, e.g. videos in sign language or with subtitles. Therefore, primarily organizational and editorial aspects are perceived by this group. Even users with reading disabilities, such as dyslexia, as well as with learning and intellectual disabilities are affected by editorial aspects so that restrictions on account of the linguistic competence are experienced.

Therefore, there seems to be a need for more awareness not only for technical aspects of accessibility but particularly for editorial aspects. All elements of a web application such as links, labels, menus and the content itself have to be formulated very carefully and as easy as possible with different user groups in mind. To check the understandability of all contents, and in particular of elements for user interactions such as forms, web applications have to be evaluated by users with a variety of abilities because these in practice experienced problems will otherwise not be detected.

\section{Acknowledgement}

I give thanks to "Aktion Mensch" and to "Stiftung Digitale Chancen" for providing the study data and the opportunity to evaluate it in that detail.

\section{References}

[1]Eimeren, Birgit von ; Frees, Beate: Ergebnisse der ARD/ZDFOnlinestudie 2010: Fast 50 Millionen Deutsche sind online - Multimedia für alle? In: Media Perspektiven 7-8 (2010), 334-349. http://www.ard-zdf-onlinestudie.de/

[2] European Commission: Assessment of the Status of eAccessibility in Europe. MeAC Measuring Progress of eAccessibility in Europe. Bonn (2007)

[3]Berger, A., Caspers, T., Croll, J., Hofmann, J., Kubicek, H., Peter, U., Ruth-Janneck, D., Trump, T.: Web 2.0/Barrierefrei. Eine Studie zur Nutzung von Web2.0 Anwendungen durch Menschen mit Behinderungen. Aktion Mensch e.V. Bonn. (2010)

[4] Caldwell, B., Cooper, M.: Guarino Reis L., Vanderheiden, G.: Web Content Accessibility Guidelines (WCAG) 2.0. W3C Recommendation. World Wide Web Consortium (W3C). December 2008. http://www.w3.org/TR/WCAG20/. (2008)

[5]Disability Rights Commission (DRC): The Web. Access and Inclusion for Disabled People. London (2004) 
[6]Lazar, J.; Allen, A.; Kleinman, J.; Malarkey, C.: What Frustrates Screen Reader Users on the Web: A Study of 100 Blind Users. International Journal of Human-Computer Interaction. 22:3, pp. 247 - 269 (2007)

[7]Lopes, R.; Gomes, D.; Carriço, L.: Web Not For All: A Large Scale Study of Web Accessibility. In: Proceedings of the International Cross Disciplinary Conference on Web Accessibility 2010. pp. 10:1-10:4 (2010)

[8] Sullivan, T. and Matson, R.: Barriers to Use: Usability and Content Accessibility on the Web's Most Popular Sites. Proceedings of the ACM Conference on Universal Usability, pp. 139-144 (2000)

[9] Sayago, S. and Blat, J.: An Ethnographical Study of the Accessibility Barriers in the Everyday Interactions of Older People with the Web. Universal Access in the Information Society. pp. 1-13 (2011)

[10] Cornelssen, I., Schmitz, C.: Vorstellung der Ergebnisse der Studie „Chancen und Risiken des Internets der Zukunft aus Sicht von Menschen mit Behinderungen“ auf der Aktion Mensch-Fachtagung „Einfach für Alle - Konzepte und Zukunftsbilder für ein Barrierefreies Internet“. http://www.einfach-fuer-alle.de/studie/. (2008)

[11] Ruth-Janneck, D.: Multidimensionale Klassifizierung von Barrieren in Webanwendungen. Mensch\&Computer 2009. pp. 13-22 (2009)

[12] Henry, S. L.: Essential Components of Web Accessibility. http://www.w3.org/WAI/intro/components.php (2005)

[13] Ruth-Janneck, D.: An Integrative Accessibility Engineering Approach Using Multidimensional Classifications of Barriers in the Web. In: Proceedings of the International Cross-Disciplinary Conference on Web Accessibility 2011. pp. 10:1-10:4 (2011)

[14] Mayer, T.: 74,75 Punkte für die Facebook-Registrierung. BIK BITV-Test. http://www.bitvtest.de/infothek/artikel/lesen/facebook-1.html (2011)

[15] Inclusion Europe: Information for all. European standards for making information easy to read and understand, http://www.inclusioneurope.org/LLL/documents/Information\%20for\%20all.pdf. Brussels. (1999)

[16] McEwan, T. and Weerts, B.: ALT Text and Basic Accessibility. Proceedings of the 21st British HCI Group Annual Conference on HCI 2008: People and Computers XXI: HCI...but not as we know it. pp. 71-74 (2007) 